\title{
O TRATO ÉTICO COM A INCLUSÃO ESCOLAR EM SOCIEDADES ADMINISTRADAS
}

\author{
Luciene Maria Silva \\ Universidade do Estado da Bahia
}

\section{Resumo:}

Este trabalho analisa os aspectos éticos envolvidos nos processos educacionais formativos que possibilitam ou não a construção de espaços para o desenvolvimento da consciência reflexiva capaz de recusar práticas discriminatórias fundadas em representações estereotipadas da diferença. Inicialmente aborda sobre a diferença como elemento de base para reivindicação da escola inclusiva numa sociedade que, por princípio, a nega ou a valoriza ao sabor dos interesses dominantes. Parte de uma compreensão sobre diversidade humana e as motivações que a negam numa perspectiva sócio-educacional, para em seguida mostrar a dinâmica do trato ético-pedagógico na escola inclusiva a partir de notas de pesquisa recente que destacam o preconceito aos incluídos da educação inclusiva. Confere particular atenção à discussão feita pelo filósofo frankfurtiano Theodor Adorno sobre a atual impossibilidade ética como doutrina da vida reta.

Palavras-chave: Inclusão; ética; diferença. 


\title{
THE ETHIC TRACT WITH SCHOOL INCLUSION IN ADMINISTERED SOCIETY
}

\begin{abstract}
This article analyzes the ethical aspects involved in the formative educational processes that enable or not the construction of spaces for the development of reflective consciousness able to refuse discriminatory practices based on stereotyped representations of difference. Initially reflects on the difference as a basis to claim the inclusive school in a society that, in principle, denies or values to according of the dominant interests. Part of an understanding of human diversity and the motivations that deny it in a socio-educational perspective thereafter to show the dynamics of ethical and pedagogical approach in inclusive school from recent research notes that highlight the prejudice to the "included students" of the inclusive education. It particularly focuses on the discussion made by the philosopher Theodor Adorno on the current ethical impossibility as doctrine of the correct life.
\end{abstract}

Key Words: Inclusion; ethics; difference. 
Dizer que a diferença é essência da humanidade, não prescinde de reconhecer, coerentemente com a história, que processos sociais produzem incessantemente novas diferenças, muitas delas constituídas como problema social no âmbito de relações assimétricas de poder. É importante mencionar essa dimensão, porque o contemporâneo é de tal forma intenso em conflitos, que se descuidamos, reduzimos o movimento da reflexão a um presentismo pragmático sem a percepção das contradições, permanências e rupturas nos processos de interação social que contrariam as continuidades perfeitas, tão a gosto do positivismo com seus tempos homogêneos e vazios (BENJAMIN, 1994).

De fato, sabemos que não existe diferença em abstrato. Elas vão se constituindo nos processos de significação definidos nos parâmetros da sociedade. A percepção sobre determinados eventos sociais, diz respeito à forma como socialmente são construídas, ou seja, às trajetórias históricas que produzem as condições para a constituição dos modos de ser. A relação entre a história pessoal e a história coletiva é carregada de conflitos e contradições tornando os processos objetivos e subjetivos relacionados à diferença um dispositivo de hierarquia e opressão ou de igualitarismo e diversidade. Logo, a diferença não pode ser compreendida de forma distanciada da sociedade que a configura, considerando a divisão social do trabalho que gera expressões de propriedade e dominação.

Diferença, pluralidade e diversidade são temas intensamente debatidos, no sentido da busca por afirmação, principalmente em função da emergência de conflitos marcados pelo realce do outro: localismos, migrações, padrões estéticos, miscigenações, sincretismos, intolerância religiosa, movimento pelos direitos humanos e tantos outros fenômenos sociais da realidade contemporânea. A continuidade da discussão, sobretudo na área de educação, evidencia a persistência de tensões que se põem para a afirmação e reconhecimento das diferenças. As abordagens críticas questionam sobremaneira as relações de poder que produzem diferenças respaldadas na Olh@res, Guarulhos, v. 3, n. 1, p. 58-75. Maio, 2015. 
desigualdade ou que as associam à prática da tolerância ou da assimilação e adaptação. Horkheimer (2002, p.24) assinala que "por um lado tolerância significa liberdade frente às normas de autoridade dogmática; por outro lado, conduz a uma atitude de neutralidade em relação a todo conteúdo espiritual, que se submete assim ao relativismo".

Os últimos anos da década de 1990 no Brasil foram marcantes para o movimento de inclusão de alunos com deficiência ou necessidades educacionais especiais na escola regular, época em que foram difundidas, com muita intensidade, idéias e formulações, principalmente por meio de documentos internacionais, com propostas concretas sobre escolarização e socialização, resultando numa desaceleração na credibilidade das instituições e programas de educação especial. Como afirma Mittler (2003) a inclusão tornou-se um movimento mundial amparado por estudos e pesquisas sobre suas possibilidades. Já se pode afirmar, conforme pesquisas realizadas, que as escolas não mais produzem resistências de grande magnitude em relação à educação inclusiva (BEYER, 2005; CROCHIK et al., 2009). A inclusão escolar vem sendo a proposta considerada necessária e viável como mecanismo para garantir oportunidades para todos nos diversos setores da sociedade, seja para dar acesso ao conhecimento socialmente elaborado, seja pela possibilidade de socialização dos indivíduos.

Contudo, as dificuldades operacionais para a permanência dos alunos com necessidades especiais nas escolas regulares têm sido atribuídas à negação da diferença, sobretudo pela relutância em se revogar as distinções entre normal e anormal, tão profundamente arraigadas, onde a anormalidade circunscreve-se nos limites do indivíduo, subtraindo suas determinações sociais. Ora, mas em que ponto e de que maneira as diferenças de que tanto falamos se tornam esse objeto tão atual de discussão? Quem define a diferença? Tem ela o mesmo peso nas atribuições em que são levadas em conta para os grupos 
diferenciados? Que dimensão ética podemos considerar no trato com as diferenças na escola, na experiência da inclusão?

Diante disso, tenho como objetivo neste ensaio apresentar uma abordagem sobre as relações entre diferença, inclusão e ética numa sociedade que apresenta fortes traços de sociabilidade forçada e objetificação das relações humanas, marcas do mundo administrado. O pressuposto básico é que numa sociedade regida cada vez mais pelo equivalente universal para as trocas, os indivíduos se mantêm na autoconservação social fragilizando a dimensão de resistência no processo de escolarização. Constitui-se assim a sociedade administrada, cujas ações organizadas e previstas têem como fim proscrever a fantasia, a criatividade e o pensamento por meio da racionalidade instrumental. Dessa forma, a diferença propugnada pela educação inclusiva, convive com a indiferença e com o preconceito, ou é reconhecida apenas como um mecanismo dos procedimentos de tolerância.

Relacionar diferença, inclusão e ética de forma estanque, sem mediação social, reveste-se em ideologia, no sentido de que dissimula a realidade que se quer analisar, posto que naturaliza as referências conceituais, seguindo o princípio de que os fatos falam por si mesmos. Nessa perspectiva e com esse pressuposto, busco analisar a dimensão ética nos processos educacionais formativos que possibilitam ou não a construção de espaços para o desenvolvimento da consciência reflexiva capaz de recusar práticas discriminatórias fundadas em representações estereotipadas da diferença. Irei me deter inicialmente sobre a diferença como elemento de base para reivindicação da escola inclusiva numa sociedade que, por princípio, a nega ou a valoriza ao sabor dos interesses dominantes. Parto de uma compreensão sobre diversidade humana e as motivações que a negam numa perspectiva sócio-educacional para, em seguida, mostrar a dinâmica do trato éticopedagógico na escola inclusiva a partir de notas de pesquisas recentes que destacam o preconceito aos incluídos da educação inclusiva. Não 
é propósito deste texto, traduzir a questão ética na sua integralidade, mas evidenciar alguns aspectos de um dos problemas clássicos da filosofia: a relação entre o universal e o particular. Confiro particular atenção à discussão feita pelo filósofo frankfurtiano Theodor Adorno sobre a atual impossibilidade ética como doutrina da vida reta.

\section{A diferença como elemento de base para reivindicação da escola inclusiva}

Estou considerando diversidade humana as variadas possibilidades de manifestação do humano, a multiplicidade de modos de ser humanos; como um componente do desenvolvimento biológico e cultural da humanidade, mas sabendo que essa diversidade, esse múltiplo, não se constrói no abstrato, porquanto está imerso num tempo, espaço, história e cultura. Como evidencia Lima (2006, p.16),

[ ] a diversidade é norma da espécie humana: seres humanos são diversos em suas experiências culturais, são únicos em suas personalidades e são também diversos em suas formas de perceber o mundo. Seres humanos apresentam, ainda, diversidade biológica. Algumas dessas diversidades provocam impedimentos de natureza distinta no processo de desenvolvimento das pessoas (as comumente chamadas de ‘portadoras de necessidades especiais').

Importa salientar que pressupostos generalistas e universalizantes constituem padrões que normatizam e instituem que as formas diferenciadas de viver, ser e estar causam disfunções. Tal estranhamento se consolida pelas normas de convívio e impedimentos formais ou simbólicos de separação entre normais e anormais, iguais e diferentes, produzindo com esse estranhamento, em função da hegemonia de um modelo, a subjugação dos modos de ser diferenciados, por meio de atitudes discriminatórias e preconceitos.

A diversidade da condição humana não está fora do contexto da diversidade cultural, elas estão imbricadas, ao separá-las corremos o risco de naturalizá-las. A reivindicação na forma organizada de respeito à diversidade é algo recente e vem gradualmente se ampliando no sentido de reconhecimento às diferenças físicas, de apreensão/percepção, étnico raciais, de gênero, de opção sexual, entre 
outras. Se, por um lado, estamos em tempos de destaques e elogios para a diversidade e a diferença, por outro, não observar a base valorativa, estética e funcional que padroniza o olhar, é cair nas ciladas da visão romântica que muito tem banalizado as propostas de inclusão social, transformando-a em reivindicação despolitizada, como se a questão fosse apenas restrita à tolerância e diversidade, sem o questionamento quanto às relações de poder que legitimam as dicotomias do tipo normal-anormal.

Apesar do reconhecimento e da valorização da diferença, que vem sendo incorporada ou investigada cada vez mais no campo da educação, tanto no que se refere aos referenciais da política educacional como nas pesquisas, sabemos que a diversidade tem sido de difícil incorporação, mesmo nas propostas de linhagem democrática. Percebemos essas tensões na luta pela garantia dos direitos sociais e individuais para os segmentos que atendem pelo nome de diferentes, tanto pelos movimentos sociais como pelos encaminhamentos jurídicos individuais, visibilizando-os cada vez mais na paisagem do cotidiano, principalmente nos grandes centros urbanos.

A evolução histórica dos direitos humanos sob a ótica da legislação favorece o reconhecimento de igualdade de direitos, possibilitando atitudes de mais tolerância na sociedade, em relação ao que poderia ser considerado estranho e anormal. Porém, esse é um aspecto que não produz modificações suficientes para a compreensão sobre o direito de individuação e diferenciação. Dessa forma, todo um contingente de pessoas com características diferenciadas do que é considerado padrão na sociedade vê-se excluído do espaço urbano das ruas, da escola, dos serviços, do trabalho e do convívio social em graus e intensidades variados no âmbito das práticas civilizatórias em andamento. Essas condições têm sido objeto de denúncia por parte de alguns movimentos sociais contemporâneos na luta pelos direitos humanos e 
pelos direitos de cidadania dando visibilidade aos direitos sociais de minorias ou populações vulneráveis.

As diferenças individuais se afirmam ou são negadas no processo de sociabilidade. É na relação entre indivíduos com seus pares na sociedade que são construídas as individualidades. Se a diversidade se constituir por diferenças que emergem como problema, que necessita de integração, presta-se a uma rejeição ou ainda à sua legitimação como desigualdade. Rejeição porque são descartadas as significações próprias pertencentes ao indivíduo ou grupo, substituídas por sentidos valorativos favoráveis a esteriotipias e estigmatizações. Com efeito, vale refletir sobre a possibilidade de o indivíduo se diferenciar numa sociedade que incessantemente busca moldá-lo para o mundo da produção e da racionalidade tecnológica. Como afirma Crochik (2011, p.117),

[...] com a divisão do trabalho cada vez mais racionalizada, a diferenciação das esferas sociais diminui; e a socialização cada vez mais ampla, produto do progresso da sociedade administrada, retira a possibilidade do particular - o indivíduo que se expressa e se contrapõe ao geral - diferenciar-se.

Assim posta no âmbito da escola, a diversidade tem se tornado um objeto de investigação privilegiado para a observação das relações entre os diferentes.e, por sua vez, das mudanças que vêm ocorrendo na sociedade que expressam interesses e necessidades não apenas relacionados ao ensino e aprendizagem, pois que outras dimensões também se manifestam.

Sendo a escola uma instituição social que espelha a sociedade onde se insere, e sendo esta excludente e dividida, vê-se pautada numa perspectiva adaptativa em função de modelos de desempenho, funcionalidade, produtividade e competitividade. Alunos em situação de inclusão destoam, por vezes, desses padrões, ou porque inventam formas alternativas de convivência, ou porque não se adaptam às rotinas unificadas dos que não respeitam singularidades, ou porque se adaptam para alem do necessário. Esse movimento de vivências 
diferenciadas tem provocado no ambiente da escola, atitudes de suspeitas e dúvidas, porque o contato e convívio com alunos diferentes perturbam e desordenam o já estabelecido como padrão, considerando as bases de referência pedagógica adotada. Isso não quer dizer que a diferença só se evidencia num contexto absolutamente favorável, o que significaria negá-la como essência da humanidade, e também ignorar as possibilidades de resistência, de contradições e conflitos na sociedade. Diante disso, cabe refletir sobre a dimensão ética no trato com a diferença na perspectiva da prática pedagógica inclusiva.

\section{O trato ético-pedagógico na escola inclusiva}

As importantes reflexões sobre ética desde os antigos, não só exprimem traços de uma dada organização social, como a intenção explícita de se tornarem universais. Discutir ética pede uma atitude de prudência, porquanto é uma reflexão que se desdobra em várias dimensões, relacionadas, por sua vez, com tantas outras disciplinas teóricas. Se focarmos numa das referências éticas da antiguidade, a busca está no viver racional, ou seja, viver conforme a razão, sendo o pensamento tido como algo superior.

Para Adorno (1993) princípios morais desde a antiguidade são reflexos da dominação social, logo se a totalidade é falsa, não pode haver vida correta na falsa. Sua obra mais sugestiva sobre questões da moral chama-se "Minima Moralia: reflexões a partir da vida danificada", sendo possível identificar traços de ironia no título, que remete à "Magna Moralia", tratado sobre ética atribuído a Aristóteles. Texto em forma de aforismos trata de temas grandiosos a partir da abordagem de pequenos gestos da experiência individual e social, porém sem apelar para princípios formais de moralidade. Explicita já no início da dedicatória ao amigo Horkheimer que "quem quiser saber a verdade acerca da vida imediata tem que investigar sua configuração

Olh@res, Guarulhos, v. 3, n. 1, p. 58-75. Maio, 2015. 
alienada, investigar os poderes objetivos que determinam a existência individual até o mais recôndito dela" (ADORNO, 1993, p.7). Identifica-se aí um lamento pela impossibilidade de a Filosofia ainda ocupar-se da vida reta, sendo isso atribuído ao conflito entre ética e razão no percurso histórico. Na obra Dialética do Esclarecimento, Adorno e Horkheimer (1985) afirmam que o programa do esclarecimento tinha como meta a dissolução do mito, substituindo-o pelo saber irracional. Esse percurso resultou na dominação da natureza externa e interna que não promoveu a saída do homem da menoridade. A racionalidade esclarecida inverteu o processo, da subjugação do homem à natureza para a subjugação da natureza ao homem: "Hoje, apenas presumimos a dominar a natureza, mas de fato, estamos submetidos à sua necessidade" (ADORNO e HORKHEIMER, 1985, p. 20).

Esse processo deu-se como desencantamento do mundo para vencer as ameaças e o medo, pela busca de equivalência induzindo à estranheza irracional. O novo, o diferente, o irreconhecido foram subordinados por meio de analogias e estereotipias, ou mesmo eliminações, buscando simplificar as demandas do pensamento: "o que não se submete ao critério de calculabilidade e de utilidade torna-se suspeito para o esclarecimento" (ADORNO e HORKHEIMER, 1985, p. 21). Essa longa dialética do esclarecimento redundou num processo irracional e a uma "irrefreável regressão", pois que, o abandono do pensamento significou o abandono do ato de esclarecer-se de fato.

Se identificarmos algum pessimismo na problematização dialética empreendida por Adorno e outros pensadores alinhados à Teoria Crítica da Sociedade, isso não autoriza, nem por eles próprios, ceder ao canto da sereia da irracionalidade esclarecida ${ }^{1}$; ao contrário, a crítica deve se impor de forma ainda mais rigorosa. Se a ética racionalmente fundamentada não se apresenta como viável, a saída

\footnotetext{
${ }^{1}$ Adorno e Horkheimer (1985) na Dialética do Esclarecimento ressignificam a passagem de Ulisses ao retornar para Ítaca, narrado por Homero no Canto XII da Odisseia, quando sabendo que iria encontrar as sereias, e desejando ouvi-las, entrega-se amarrado ao mastro para não sucumbir à morte.

Olh@res, Guarulhos, v. 3, n. 1, p. 58-75. Maio, 2015.
} 
vislumbrada está em proceder a crítica às condições e circunstâncias que a impedem, revelando a violência inerente às relações sociais que leva ao ajustamento e a eliminação das diferenças. Isso quer dizer que pensar a moral demanda uma teoria social crítica, considerando que princípio moral e princípio social são indissociáveis. Adorno (1985) propõe a negação determinada da moral, ainda que para evidenciar o quanto ela é imoral.

Não se trata de admitir aplicabilidade imediata dos conceitos e enunciados, mas de investir nas possibilidades dialéticas inerentes ao próprio pensamento, no sentido de se contrapor ao comportamento economicamente racional. A dificuldade está no fato de que a consciência não apenas se impede de perceber, como também o pensamento não se pensa a si próprio. E a ideologia, que antes operava como um véu da realidade, falseando-a, pelo menos anunciava um mundo possível. Estamos em tempos em que ideologia e realidade correm uma para outra. Essa formulação de Horkheimer e Adorno (1973) é bem sintetizada por Crochik (2011, p.81-82), quando afirma:

\footnotetext{
$\mathrm{Na}$ atualidade, a ideologia tecnológica, ou relativista, ou pós-moderna, ou qualquer nome que receba, consiste em voltar o pensamento à sua utilidade imediata, ou seja, ao julgamento dos meios, uma vez que os fins já foram fixados de antemão: a manutenção de regras impróprias ao convívio humano - a lei do mais forte, a lei da competição -, ambas ancoradas na violência, que, em um mundo racional, deveria ser eliminada.
}

Mesmo admitindo que os processos de adaptação são necessários, isso não significa subtrair da escola, como um território privilegiado para tal fim, sua possibilidade de resistência à tendência de uniformização e negação da individualidade, uma vez que tal assertiva autoriza a sua caracterização como uma instituição social e burocrática com função destinada apenas à distribuição, seleção social e transmissão de conteúdos culturais e científico. Isso negaria qualquer possibilidade à escola de, pela sua natureza que se evidencia como um campo de tensão social, criar bases para o desvendamento dos mecanismos de dominação. Assim, considero que o trato pedagógico na escola para 
com a diferença deve evidenciar uma compreensão crítica rigorosa acerca da igualdade abstrata propagada socialmente e nas políticas oficiais.

A simples convivência com os diferentes não é suficiente para obstar um julgamento negativo e prévio ainda tão internalizado nas relações sociais, em função do quadro de agressão simbólica e material cotidianamente direcionada às pessoas com deficiência. Os processos de segregação social são determinantes para a produção e reprodução da anormalidade; daí que a mera convivência com a diferença por si só, sem a alteração das condições sociais torna a proposta de inclusão escolar apenas um reparo social com vistas a ordenar e administrar as relações que se mostram tensas, contraditórias, conflituosas, dado a recusa e encobrimento dos seus postulados.

É importante ressaltar que a inclusão de crianças e adolescentes com deficiência na escola comum não é um fenômeno isolado no âmbito do sistema educacional brasileiro, uma vez que outras categorias populacionais também reivindicam acesso e permanência à instituição escolar. Conforme Kassar (2011), sob o impacto de documentos internacionais que anunciavam preocupações econômicas, sobretudo em relação aos países em desenvolvimento, a exemplo da Declaração Mundial sobre Educação para Todos (1990), Plano Decenal de Educação para Todos (1993) e a Declaração de Salamanca (1994), várias nações passam a incorporar nas suas políticas educacionais, a discussão sobre inclusão escolar: "Sem desconsiderar os movimentos em prol de situações menos segregadoras para pessoas com deficiências, acreditamos que a implantação e uma política de "educação inclusiva" deve ser analisada no contexto complexo das políticas sociais das sociedades capitalistas" (KASSAR, 2011, p.71). Assim, este é um fenômeno histórico das sociedades contemporâneas, com seus condicionantes econômicos e políticos, no âmbito de reformas educacionais preconizadas pelas agencias de regulação do capitalismo. 
Evidentemente, a proposta de inclusão no contexto da democracia formal incorpora ideais liberais, na medida em que secundariza a atenção para as condições que a tornam possível. O tom salvacionista ou mesmo pragmático que se imprime à educação esconde as contradições sociais, atribuindo-lhe força para produzir justiça social. Porém, defender a inclusão de segmentos sociais marginalizados com políticas afirmativas é, também, um caminho que expressa possibilidades humanizadoras, bem como o desejo de superação da condição objetiva que determina a exclusão social. Como já afirmado em outro texto, é necessário "diferenciar a crítica identificando os aspectos de resistência dos que se opõem à afirmação da diferença, pois, no fundo, esta é uma ameaça para a hegemonia de uma minoria que se fortalece pela desigualdade institucionalizada, que produz e reproduz insistentemente as anormalidades" (SILVA, 2008, p.131).

O aspecto mais destacado como obstáculo à inclusão escolar, tanto por professores e estudiosos, quanto pelos gestores da política educacional, é a formação docente. Contudo, a preocupação restrita à formação de professores não é suficiente perante a constatação de um sistema de ensino que, ao longo da história tem reproduzido persistentemente processos de marginalização de um contingente considerável de estudantes. O desafio está em tornar possível uma escola qualificada para todos garantindo respeito às especificidades dos que a reivindicam.

Consoante a esses pressupostos, pesquisas indicam que ainda prevalecem situações adversas relacionadas à inclusão de alunos com necessidades educacionais especiais, seja nas escolas públicas, privadas ou nas universidades (FRELLER, 2010; CROCHIK, 2013). Esse é um aspecto que fortalece nossa perspectiva quanto à necessidade de nos voltarmos para a crítica das condições sociais necessárias ao exercício ético. 
Em pesquisa recente (SILVA et al., 2014) $)^{2}$, com o objetivo de compreender a correspondência entre o grau de inclusão de uma escola e o nível de segregação e marginalização dos alunos incluídos em quatro escolas das redes pública e privada, coletamos dados com gestores, professores e alunos do ensino fundamental por meio de entrevistas e observações. Uma primeira constatação é a de que, embora a política educacional brasileira proponha e recomende a inclusão escolar, alunos com deficiência continuam sendo categorizados mesmo em classes regulares. Os professores já não mais resistem à orientação da inclusão escolar, aspecto que pode ser atribuído à promoção da formação continuada pelas secretarias de educação, embora ainda observam-se apelos explícitos por uma formação específica em educação especial, para os que atuam em classes com alunos em situação de inclusão. Contudo, não é percebido que, contemporaneamente, a apropriação de vários conhecimentos e informações antes não exigida, tem sido uma necessidade, conquanto tenham chegado novos perfis de alunos e de componentes curriculares. A atuação linear em sala de aula tornou-se um obstáculo para o professor atuar em classes heterogêneas.

Assim, apesar das mudanças significativas nas percepções dos agentes educacionais em relação à educação inclusiva como política educacional no Brasil, a realidade que se apresenta nas escolas pesquisadas ainda se constitui como obstáculo que se impõe como forma dissimulada de exclusão: escolas sem adaptações na estrutura arquitetônica ignorando a necessária acessibilidade; inexistência de materiais adaptados e ou recursos didáticos; acompanhamento precário dos centros de apoio especializados ou ausência de salas de recursos multifuncionais; concepções pedagógicas meritocráticas que promove os 'melhores', veiculando a crença de que 'alunos de inclusão' retardam os processos coletivos de aprendizagem em classe.

\footnotetext{
${ }^{2}$ A pesquisa "Preconceito aos 'incluídos' na educação inclusiva", de autoria do Prof. José Leon Crochik da Universidade de São Paulo foi realizada em várias cidades no Brasil. Em Salvador (BA) foi coordenada pela Prof. Luciene Maria da Silva no período de 2009 a 2013 e teve financiamento da Coordenação de Aperfeiçoamento de Pessoal de Nível Superior (CAPES).

Olh@ res, Guarulhos, v. 3, n. 1, p. 58-75. Maio, 2015.
} 
É de se notar, contudo, que a condição precária da educação escolar no Brasil não se restringe à educação especial, pois

[...] alcança grande contingente de alunos, com ou sem necessidades especiais, seja porque nela não permanecem, seja porque prosseguem sem o tempo necessário para a apropriação devida de saberes que os qualifiquem para a vida adulta, somado ao fato de que esse tempo também não é otimizado para a formação (SILVA et al., 2014, pg. 19).

A tendência tem sido uma supervalorização da formação especializada, como se apenas o conhecimento específico, principalmente o didático metodológico, viesse a dar conta do desempenho docente qualificado e necessário para promover a aprendizagem de alunos com necessidades especiais. A percepção tem sido mais focalizada no conhecimento que vem de fora, pronto e administrado para ser consumido, o que expressa uma rigidez na compreensão da deficiência como anormalidade ou impossibilidade para aquisição de conhecimentos e habilidades. Dessa forma, os professores também paralisam seus esforços no sentido de estimular as interações entre os alunos em classe (SILVA et al., 2014).

Além disso, persistem nas instituições de ensino superior situações absurdas de inacessibilidade que negam a afirmação das diferenças, seja no âmbito organizacional, arquitetônico ou atitudinal. Faz-se necessário, a priori, desenvolver culturas de afirmação e valorização das diferenças que possibilitem a inclusão e permanência do aluno, retirando dele a responsabilidade única pela sua aprendizagem, característica do processo de integração. $\mathrm{O}$ despreparo dos professores formadores para essa discussão é equivalente ao que costumamos identificar em relação aos professores do ensino básico. Não é possível pensar em formação de professores com o foco no domínio do conhecimento pedagógico ou nas competências e habilidades necessárias para atuação nas escolas inclusivas. Sendo a universidade uma instituição social que expressa a sociedade onde está inserida, com suas contradições e conflitos, consideramos possível, pela reflexão, retomar a sua função formativa, como adverte Adorno (1995, Olh@res, Guarulhos, v. 3, n. 1, p. 58-75. Maio, 2015. 
p.139 ) em seus escritos sobre educação: "para que a reflexão não se restrinja à formação, para que? ou educação, para que? a intenção, deve ser no sentido de compreender para onde a educação deve conduzir".

Decerto que a afirmação de valores favoráveis à diferença e a diversidade humana, além do combate à discriminação e preconceito torna-se um imperativo para a prática pedagógica. A escola como lugar de educação formal, apesar de refletir o contexto social em que está inserida, não pode intensificar o sempre igual e a violência objetiva que incorpora. A tensão está em que, ao mesmo tempo em que ela reproduz a perspectiva liberal, pode contribuir no combate às injustiças sociais, posto que lida com formação. Diante disso é pertinente considerar a dimensão ética fundamental da educação inclusiva que diz respeito ao direito de todos à escolarização, entendendo-a na perspectiva de entrada e permanência de todos os alunos na escola.

Finalizando, em tempos de renovação da barbárie, a possibilidade de se pensar uma articulação entre ética, diferença e inclusão está na reflexão sobre as condições que limitam a constituição da individualidade, as mesmas que viabilizam a organização social irracional que impede a liberdade e a atividade pedagógica para realização da formação. Nesse sentido, retomando o pressuposto por Adorno sobre a impossibilidade de uma vida ética numa sociedade que ainda não comporta a vida justa, podemos pensar no ideal de vida não realizada, como referência para a crítica e para um devir de liberdade e afirmação da diferença. 


\section{Referências bibliográficas}

ADORNO, Theodor W. Educação e emancipação. Rio de Janeiro: Paz e Terra, 1995.

ADORNO, Theodor W. Minima Moralia: reflexões a partir da vida danificada. São Paulo: Ed. Ática, 1993.

ADORNO, Theodor W. e HORKHEIMER, Max. Dialética do Esclarecimento. Rio de Janeiro: Zahar Ed., 1985.

BENJAMIN, Walter. Sobre o conceito de história. In: Obras Escolhidas: Magia e Técnica, Arte e Política. São Paulo: Brasiliense, 1994.

BEYER, Hugo. O. Inclusão e avaliação na escola. Porto Alegre: Mediação, 2005.

CROCHIK, José Leon. O desencanto sedutor: a ideologia da racionalidade tecnológica. In: _. Teoria Crítica da sociedade e Psicologia : alguns ensaios. Araraquara, São Paulo: Junqueira Marin; Brasilia, DF: CNPQ, 2011.

et al. Educação inclusiva: escolha e rejeição entre alunos. Psicologia $e$ Soc. 2013, vol.25, n.1 [citado 2015-05-20], pp. 174-184 . Disponível em: <http://www.scielo.br/scielo.php?script=sci_arttext\&pid=S0102-

$71822013000100019 \& \operatorname{lng}=\mathrm{en} \& \mathrm{nrm}=\mathrm{iso}>$.

ISSN 1807-0310. http://dx.doi.org/10.1590/S0102-71822013000100019.

et al. Atitudes de professores em relação à educação inclusiva. Psicologia: Ciência e Profissão, Brasília, v. 29, n.1, p. 40-59, 2009.

FRELLER, Cintia Copit. É possível ensinar educadores a incluir?: Como ensinar educadores a ensinar alunos de inclusão?. Estilos clin. [online]. 2010, vol.15, n.2 [citado 2014-12-14], pp. 326-345 . Disponível em: <http://pepsic.bvsalud.org/scielo. php?script=sci_arttext\&pid=S1415-71282010000200004\&lng=pt\&nrm=iso $>$. ISSN $1415-7128$.

HORKHEIMER, Max. e ADORNO, Theodor W.. Temas Básicos de Sociologia. São Paulo: Cultrix, 1973.

HORKHEIMER, Max. Eclipse da Razão. São Paulo: Centauro, 2002.KASSAR, Mônica de C. M. Educação especial na perspectiva da educação inclusiva: desafios da implantação de uma política nacional. Educar em Revista, Curitiba, Brasil, n. 41, p. 6179, jul./set. 2011. Editora UFPR.

LIMA, Elvira de Souza. Currículo e desenvolvimento humano". In: MOREIRA, Antonio Flávio e ARROYO, Miguel. Indagações sobre currículo. Brasília: Departamento de Políticas de Educação Infantil e Ensino Fundamental, nov. 2006, p.1147.

MITTLER, Peter. Educação Inclusiva: contextos sociais. Porto Alegre: Artmed, 2003.

SILVA, Luciene M. Diferenças negadas: o preconceito aos estudantes com deficiência visual. Salvador: Eduneb, 2008.

Olh@res, Guarulhos, v. 3, n. 1, p. 58-75. Maio, 2015. 
SILVA, Luciene M.; SANTOS, Jaciete B. DOURADO, Jamara. Preconceito aos 'incluídos' na educação inclusiva: um estudo em quatro escolas de Salvador (BA). In: Estudos sobre preconceito e inclusão educacional. Salvador: EDUFBA, 2014.

Recebido para publicação em 16 de dezembro de 2014 Aprovado em 15 de abril de 2015. 